completely. Thus this method of working provides us with the possibility of distinguishing these two groups of substances biologically from one another.

The cause of the different action of diethylstilbœstrol is at present being investigated more closely.

Pharmaco-therapeutic Institute, O. MÜHLBOCK. University, Amsterdam. Dec. 19.

${ }^{1}$ Mühlbock, Acta Brevia Neerland., 8, 50 (1938).

2 Dodds, Golberg, Lawson and Robinson, NAruRE, 141, 247 (1938).

${ }^{3}$ Mühlbock, Acta Brevia Neerland., 9, No. 1 (1939).

- Comprehensive description by Freud, Abderhaldens Handbuch, 5. 3B, $1667(1938)$

\section{Cycle of Responsivity of Castrated Albino Mice and of Human Beings to Estrone Injection}

IN her recently reported observations on seasonal rhythm in the responsiveness of castrated mice to injections of œstrone, Dr. J. Duszyńska states that the response is more than three times as great in May as in November ${ }^{1}$. She raises the question as to whether a similar rhythm exists in the human.

Such an observation, of course, is somewhat difficult to correlate with studies made on the human female whose gonads are still present and functioning cyclically. There does appear to be a seasonal rhythm, however, in the values for blood œstrogens found in normal males ${ }^{2}$. Moreover, it is much more common to find high values for blood nestrogens ${ }^{3}$ in pregnant women in the late winter and spring than in the summer, in this part of Canada at least. This can be correlated with an increase in the late winter and a decrease in summer in the incidence of pathological states closely related to high values of blood œstrogen, such as certain pregnancy toxæmias and abortion. We have postulated, on account of the reciprocal relation existing between ingested vitamin $\mathbf{E}$ and the blood ostrogen, that this is due to the seasonal tides in intake of this vitamin. In administering anti-œstrogens it is essential to take this variation into consideration ${ }^{4}$.

If Duszyniska means that only one third as much œstrogen has to be administered in May as is required in November in order to produce the same degree of response, her data parallels ours.

University of Western Ontario,

$$
\text { E. V. SHuTE. }
$$
London, Canada.

$$
\text { Dec. } 6 .
$$

${ }^{1}$ Duszyńska, J., Nature, 142, 673 (1938).

2 Shute, E. V., Amer, J. Ob. and Gyn., 35, 6.99 (1938).

${ }^{3}$ Shute, E. V., J. Ob. and Gyn. Br. Emp., 43, 74 (1936).

"Shute, E. V., Can. Med. Assoc. J. (in the Press).

\section{Effect of Zinc on the Iodine-Consuming Power of Insulin}

THE duration of the blood sugar lowering action of insulin injected by the subcutaneous route is prolonged by the addition of zine salts ${ }^{1}$. The action of crystalline insulin containing zine is of longer duration than that of an equal number of units of a preparation free from zinc.

This zinc effect is not found when rabbits are used, since apparently no difficulties are encountered in the assay of insulin of varying zinc content by the widely used rabbit method. Experiments with diabetics, however, have shown that this zine effect is readily demonstrable $e^{2,3}$, and rather severe clinical disturbances were observed when a crystalline insulin was substituted for a zine-free preparation (insulin containing less than $0.1 \mathrm{mgm}$. zinc per 1000 units is considered zinc free) ${ }^{4}$.

As the onset of the action of insulin appears to be retarded in the presence of $\mathrm{zinc}^{3}$, one is led to the assumption that the insulin cannot become fully active unless the zinc, which shields an active part of the molecule (by the strong hydration of the zine ion ?), is split off.

With the view of finding out whether zinc exerts a protecting action also in vitro, I examined the action of iodine on insulin. The iodine-consuming power of insulin was measured at $p \mathrm{H} 7 \cdot 2$ in the presence of calcium, aluminium, cadmium, zine and lead.

It was found that the addition of zinc (and to a smaller degree probably also of cadmium) decreased the iodine consumption. Calcium, aluminium and lead showed no effect. The magnitude of this zine effect is a function of the physiological activity of the insulin preparation used. These findings suggest the possibility of a purely chemical explanation of the physiological effect of zinc on the action of insulin. Moreover, a chemical method of assay of insulin appears to be made possible by the fact that my experiments showed the existence of a definite rela. tion between the iodine-consuming power of insulin and its physiological action as measured in units.

Details of the experimental results will be pub. lished elsewhere.

Pharmaceutical Department

\section{E. H. Vogelenzang.}

Municipal and University Hospital, Utrecht.

Dec. 23.

Scott, Fisher, J. Pharmacol. and Exper. Therap., 55, 206 (1935). ${ }^{2}$ Rabinowitch, Foster, Fowler and Corcoran, Canad. Med. Assoc. J., 35, 239 (1936)

${ }^{3}$ Hulst and Vogelenzang, Nederl. Tijdschr. v. Geneesk., 81, 1916 (1937).

- Vogelenzang and Hulst, Acta Med. Scandin., 97, 307 (1938).

Chlorophyll Formation and Development of Photosynthetic Activity in Juvenile Leaves of Mango (Mangifera indica)

The question how far the development of photosynthetic activity is concomitant with chlorophyll formation has not been definitely answered; the investigation in higher plants being mainly along two lines: (1) relationship between rates of photosynthesis and chlorophyll formation in leaves in different stages of development ; and (2) relationship between the two during the greening of etiolated seedlings.

(1) Willstätter and Stoll ${ }^{1}$ observed that in the developing leaf both the chlorophyll content and photosynthetic rate increase but not in any definite proportion. Singh and $\mathrm{Lal}^{2}$ noted that mature and old leaves, although containing a greater amount of chlorophyll than the younger, fail to show a proportionate increase in the photosynthetic rate. Briggs $^{3}$ finds in seedlings developing a specialized photosynthetic organ different from the storage, the activity is not developed until some time after germination, while in those with the storage and the first assimilatory organ the same, there is no lag between the development of chlorophyll and that of full photosynthetic activity.

(2) Irving ${ }^{4}$ concludes that chlorophyll is not a limiting factor in the earlier stages of the developing 